\title{
Futuristic Approach to Environment Cleansing: Bioremediation
}

\author{
Poonam Shakya*, Anju Nayak, Joycee Jogi, Ajay Rai, Smita Bordoloi, \\ K. Himani and Aishwarya Lade
}

Department of Veterinary Microbiology, College of Veterinary Science \& Animal Husbandry, NDVSU, Jabalpur (MP), India

*Corresponding author

\section{A B S T R A C T}

\begin{tabular}{|l|}
\hline K e y w o r d s \\
Bioremediation, \\
Microbes, \\
Pollutants, \\
Ecofriendly, \\
Environment. \\
\hline Article Info \\
\hline $\begin{array}{l}\text { Accepted: } \\
\text { 07 August } 2020 \\
\text { Available Online: } \\
\text { 10 September } 2020\end{array}$ \\
\hline
\end{tabular}

\begin{abstract}
The increase in the rate of urbanization has dawned many advantages and disadvantages of varying degree to the life forms on earth. The recent years have seen the emergence of a wide variety of factors that has caused pertuberance to the environment as well as to the health of the human. One of the serious problems requiring immediate consideration is the pollution of the environment has it harbors risk to the humans and other life forms coinhabiting the earth. Therefore it is of utter demand for the necessity of a remediating strategy for the environment and under such a scenario, the Bioremediation hails as a better tool. The Bioremediation employs microbes as well as certain plants for the process of remediating the environment and is considered to be a ecofriendly waste management technique which is capable of eradicating or neutralizing the persistence of environmental pollutants. The most commonly employed microbial bioremediators are Acaligenes, Actinobacter, Arthrobacter, Flavobacterium, Mycococcus, Methylosinus, Nitrosomonas, etc.
\end{abstract}

\section{Introduction}

The recent years have brought the advent of several novel technologies with the efficiency to eradicate the pollutants prevailing in the environment with the ability to cure a significant damage to the human health (Das et al., 2019). The increased level of industrial revolution and lifestyle changes has come with the serious impact on the environment in the form of pollution. The pollution is a kind of cancer that has the potential to debilitate the efficiency of the environment. The negligence and carelessness imparted by us to environment has reflected back in the accumulation of the pollutants in the environment we inhabit. Hence it of utmost importance to remediate our environment back to normal stage. The conventional techniques of physical and chemical remediation of the environment are highly cost as well as time consuming and hence there is a need for the biological remediation strategy to intervene in the form of Bioremediation (Song et al., 2019). The process of Bioremediation employs microorganisms in major capacitated with the ability to perform degradation of hazardous 
organic pollutants from a toxic level to a non lethal level in the various environmental bodies like the soils, sediments, ground water, etc (Pandey and Fulekar, 2012). This process is a waste management technique that facilitates the use of micro- organisms, plants and microbial metabolites for the efficient removal as well as the neutralization of pollutants that are prevalent in a particular environment (Shekhar et al., 2020). This type of a biological approach is a powerful scientific technology that is capable of utilizing the intrinsic as well as generated properties of the Phytobased flora as well microflora with special emphasis to the bacteria, fungi, yeast, as well as the algae. The various Microorganisms and plants employed for the purpose of bioremediation are commonly referred to as the bioremediators (Desoky et al., 2020). These bioremediators are potential candidates that are capable of conferring a highly efficient, cost-effective and environmentally friendly outcomes with extreme abilities for tackling the infested condition of the environment with pollutants. The emergence of such toxic pollutants are generally due to their associated release from various industries and facilitate a great risk to the life inhabiting on the land as well as the water bodies. Some of the important environmental pollutants are polychlorinated biphenyls (PCBs), bisphenol A (BPA), pharmaceutical wastes, polycyclic aromatic hydrocarbons (PAHs), hospital effluents, heavy metals, dyes and disinfectant by-products (Mohapatra et al 2010; Padhye, 2016; Dharupaneedi et al., 2019).

The pollution of the Environmental is a global concern and is result of the rapid progress that occurred in industrialization, urbanization as well as in the modern development to form a technologically advanced community. Innovations in the industrial technology have given rise to the birth of several novel compounds which possess the power to persist as pollutants which are above the degradation capacity of the environment. At present, with the birth of Environmental biotechnology, the need for remediating strategy has led the focus of researchers to the exploring of avenues in the process of bioremediation for the protection of the environment. This review provides a bird's eye view on the insights of Bioremediation and its role in environmental restoration.

\section{Importance of bioremediation}

The importance of Bioremediation and its feasibility in serving as an environmental friendly strategy for the restoration of the environment can be attributed to the following perspectives associated with the application of remediation using biological agents:

\section{Lack of employment of chemicals}

The major issue with the application of chemical remediation process is the involvement of man-made chemicals for the treatment which itself has a contaminating ability that can cause impact to the environment in the aftermath by leeching into the ground soil and water supplies (RiserRoberts, 1998). Several chemicals have been employed at the beginning for the management of which were identified to be very harmful to the plants, animal and the human life as they had the ability to be bioaccumulated in the food chain. This kind of a threat is completely absent with the application of bioremediation as it involves on the application of biological agents with a good degradation capacity.

\section{Recycling of wastes generated}

The other major reason favoring the feasibility of bioremediation is the recycling 
of the products formed by the result of pollutant degradation which is an impossible phenomenon in the chemical remediation strategies as the end products still display the attributes of contaminants and cannot be subjected to the recycle process. The process of Bioremediation permits the recycling of wastes thereby efficiently neutralizing the impact of environmental pollutants (Gavrilescu, 2005).

\section{Principles of bioremediation}

The principles of bioremediation are based on the type of remediator involved and could be accessed by the plant based as well as the microbial bioremediation. The major biological agents involved in the process of bioremediation belong to bacterial origins as these microscopic organisms possess the ability to virtually colonize in any type of environment. The Microbial bioremediators are considered to be more compatible for the degradation of contaminant as they possess the ability to produce enzymes as metabolites. These microbial metabolites facilitate their application in the removal of environmental contaminants as they are small and can therefore contact the contaminants easily thereby by structuring the principal of bioremediation.

The process of In situ bioremediation can be regarded as the extension of the purpose of existence of the microorganisms that has naturally been serving the environment for billions of years by performing the breakdown of complex human, animal, and plant wastes into simple forms. This kind of a degrading potential possessed by the microorganisms is crucial for preventing the earth from being buried in the generated wastes and this kind of burial can lead to the unavailability of nutrients necessary for the existence of life from the detritus (National Research Council, 1993).

\section{Classes of bioremediation}

\section{In-situ}

The class of In situ Bioremediation defined as the process of bioremediation which is done on the contaminants at the point of origin. For instance, in the bioremediation of a pollutant infested soil, the treatment process is carried out at the contaminated site rather than removing the soil from its origin and transporting it to a decontamination site which in fact is an intensive process both in terms of time as well as expense. The major beneficial impact associated with the in situ treatment is the prevention of the spread of contamination by the pollutants that may occur during the displacement of the contaminated material from its origin to a treatment site (National Research Council, 1993).

\section{Ex-situ}

The class of Ex situ bioremediation refers to the treatment of polluted site that occurs after the displacement of the contaminated substance from the origin to a site specially allocated for the treatment purpose. For instance, in the case of soil treatment, the soil can be displaced and transported to an area for the application of the bioremediation processes. The major advantage associated to this is that it aids in the containment and control of the bioremediation products along with the facilitation of the contaminated site as an available site for use (Beškoski et al., 2011).

\section{Types of bioremediation}

\section{Phytoremediation}

This type of process refers to the application of plants for the efficient removal of the contaminants. The plants that function as the 
bioremediator are capable of absorbing the contaminants from the surrounding environment into their physical structures and integrate tightly with them thereby effectively removing them presence from soil or water (Ashraf et al., 2019).

Bioventing: this refers to the process of blowing air through soil for the purpose of increasing the rates of rates of oxygen in the polluted body which acts as an effective method for the neutralization of certain oxygen sensitive metals or chemicals that are present in the polluted site (Varshney, 2019).

\section{Bioleaching}

It is the process of employing bacterial agents for the dissolving of metals rather than being dependent on the chemical solutions. Metals such as zinc, nickel, copper, gold, cobalt, lead, arsenic etc. are often removed from polluted sources by Bioleaching which employs specific bacteria capable of targeting the metal (Varshney, 2019).

\section{Land farming}

Land farming is considered as a ex-situ waste treatment process performed in the upper soil zone or in the biotreatment cells. In this process, the contaminated sediments, soils, or sludges are transported to the land farming site and are incorporated into the soil surface which are periodically turned over (tilled) for the aeration of the mixture (Varshney, 2019).

\section{Composting}

Composting is referred to as the process of recycling the decomposed organic materials into the rich soil which is called the compost this process helps in the restoring of nutrients back into the soil for increasing its fertility (Varshney, 2019).

\section{Bioaugmentation}

Bioaugmentation is referred to as the practice involving the addition of cultured microorganisms into the subsurface of the environment for the purpose of biodegrading the specific soil as well as the groundwater contaminants (Raper et al., 2018).

\section{Rhizofiltration}

This refers to the process of phytoremediation that involves the filtering of water through a mass of roots which serve as a sieve in the removal of toxic substances and excess nutrients from the water (Ashraf et al., 2019).

\section{Biostimulation}

This refers to the process of modification of the environment for the stimulation of the existing bacteria to be capable of bioremediation and can be done by the addition of various forms of rate limiting nutrients as well as electron acceptors, such as phosphorus, oxygen, nitrogen, or carbon, etc. to the environment (Varshney, 2019).

\section{Bioremediation using nanotechnology}

The contaminants whether they are organic or inorganic irrespective of their composition serve as a threat for the environment and human health with their presence as well as persistence increasing rapidly. It is for this reason that several existing technologies including the process of bioremediation in combination with the nanotechnology have been investigated for the advent of more systemic approaches aimed in the restoration of the environmental matrices.

The interaction between the pollutant, the microorganism and the nanomaterials (NMs) is considered to be of crucial importance for the evaluation of the positive as well as the 
negative effects produced. For instances, some of the nanomaterials are considered to be stimulants for microorganisms, while others are considered to be toxic. Hence a proper selection is of paramount importance for their application in Bioremediation (Vázquez-Núñez et al., 2020).

Different kinds of nanoparticle have been evaluated for the determination of their potential in the reduction of contaminants thereby helping in the nourishment of living organisms. The selection of the type material for the synthesis of nanomaterial capable of bioremediation depends on the nature of the contaminant that pollutes the environment. Some of the widely employed Nanomaterials for bioremediation include the magnetite for separating the heavy metals in soils or water through its magnetic properties, carbon-based NMs for trapping organic pollutants or heavy metals from water, soil or air, etc (VázquezNúñez et al., 2020).

\section{Common organisms employed in bioremediation}

The common microbial agents employed for the purpose of Bioremediation are referred to as bioremediators and are employed in diverse environments. These bioremediators are generally identified as the active members of microbial consortiums with remarkable property of degradation. Some of the remediators are: Acinetobacter, Actinobacter, Acaligenes, Arthrobacter, Xanthofacter, Bacillins, Serratio, Berijerinckia, Methylosinus, Nitrosomonas, Flavobacterium, Mycrobacterium, Mycococcus, Nocardia, Penicillium, Phanerochaete, Pseudomonas, Rhizoctomia and Trametes (Pandey and Fulekar, 2012) (Table 1).

Table.1 Essential factors for microbial bioremediation

\begin{tabular}{|c|c|}
\hline Factor & Desired Conditions \\
\hline Microbial population & $\begin{array}{l}\text { Suitable kinds of organisms capable of } \\
\text { biodegrading contaminants }\end{array}$ \\
\hline Oxygen & $\begin{array}{l}\text { Sufficient to } \\
\text { aerobic biodegradation (about } 2 \% \text { oxygen in } \\
\text { the gas phase or } 0.4 \mathrm{mg} / \text { liter in the soil water) }\end{array}$ \\
\hline Water & $\begin{array}{l}\text { Soil moisture should be approximately be } 50 \\
70 \% \text { of the water holding capacity of the soil }\end{array}$ \\
\hline Nutrients & $\begin{array}{l}\text { Nitrogen, sulfur, phosphorus and other } \\
\text { nutrients for supporting good microbial growth }\end{array}$ \\
\hline Temperature & $\begin{array}{l}\text { Appropriate temperatures for the microbial } \\
\text { growth }\left(0-40^{\circ} \mathrm{C}\right)\end{array}$ \\
\hline pH & Best range is from 6.5 to 7.5 \\
\hline
\end{tabular}

\section{Advantages}

Bioremediation is considered to be a natural process perceived as an acceptable strategy for waste treatment of contaminated environmental bodies such as the soil, water, etc. Theoretically, the process of bioremediation aids in the complete degradation of a wide variety of contaminating pollutants. Many pollutants that are legally considered to be toxic can be converted into harmless non toxic end products. This leads to the elimination of a possibility of future liability that is associated 
with the treatment as well as the disposal of the contaminated material. Instead of the transfer of contaminants from one environmental medium to another medium as for instance in the case of transfer from land to water or air, the complete degradation of a target pollutant is highly possible with less disturbances to the environment. The process of Bioremediation is often carried out on site with less disruption to the normal activities which thereby favors its employment for environmental cleanup. This kind of a onsite elimination nullifies the need for the transportation of the polluted substances from the site of origin thereby eradicating the threats to human health and the environment that can possibly occur during the transportation. The major advantage of Bioremediation is that it employs the resources that available in the nature for the decontamination thereby proving to be a less expensive technology that can be used for cleanup of hazardous wastes (Chawla et al., 2013).

\section{Disadvantages}

Despite having numerous advantages, the process of Bioremediation is also accompanied with several disadvantages as they can sometimes end up in the partial degradation of the contaminant thereby leading to the presence of toxic residues that can be potentially volatile in certain cases. Hence there is a requirement for extensive monitoring throughout the process. Remediation processes are generally expensive, labor intensive and can also consume several months for the remediation results to achieve an acceptable level. The time consumptions were found to be prolonged in the case bioremediating pesticides when compared to other possible detoxifying processes (Nie et al., 2020). The process of bioremediation is also very difficult to be extrapolated from the laboratory scale investigations to the field operations. It was also reported that the release of genetically modified microorganisms into the environment can in certain cases render them difficult to remove after a certain point of time. The other major drawback is the use of in situ and ex situ processes that are capable of causing excessive damages more than the actual pollution itself. These biological processes are often considered to be highly specific in nature. The various important factors required for accessing the success of bioremediation comprise of the presence of metabolically active microbial populations, favorable environmental conditions for growth and the presence of appropriate levels of nutrients as well as the contaminants (Chawla et al., 2013).

In conclusion the environment we live in a inherited property from our ancestors and we should ensure the safety of it as we have to pass it on to our upcoming generations. Hence it is our major responsibility to restore the health of the environment. The process of bioremediation possesses advantageous potential in the restoration of our environment back to normality. The technique of Biomolecular engineering should be further exploited with emphasis for the improvisation of the capabilities of the bacteria or the metabolic enzymes for facilitation in remediating systems. The development of bacteria that are genetically engineered for displaying enhancements in their abilities to degrade the different types of substances under the field conditions can further improvise the efficiencies of the Bioremediation. Further explorative researches are required for the investigation of the bioremediation potential of several recombinant as well as indigenous bacteria for their application as bioremediators. The efforts must be emphasized directly towards the faste rand efficient restoration of polluted 
bodies of the environment for the purpose ensuring quality health to all the living forms inhabiting the earth (http://shodhganga.inflibnet.ac.in/bitstream/1 0603/3703/15/15_chapter\%207.pdf).

\section{References}

Ashraf, S., Ali, Q., Zahir, Z. A., Ashraf, S., and Asghar, H. N. (2019). Phytoremediation: Environmentally sustainable way for reclamation of heavy metal polluted soils. Ecotoxicology and Environmental Safety, 174, 714-727.

Beškoski, V. P., Gojgić-Cvijović, G., Milić, J., Ilić, M., Miletić, S., Šolević, T., and Vrvić, M. M. (2011). Ex situ bioremediation of a soil contaminated by mazut (heavy residual fuel oil)-A field experiment. Chemosphere, 83(1), 34-40.

Chawla, N., Suneja, S., Kukreja, K. and Kumar, R. (2013). Bioremediation: An emerging technology for remediation of pesticides. Research Journal of Chemistry and Environment, 17 (4), 88105.

Das, S., and Bhattacharya, S. S. (2019). BioNano Interfacial Interactions of Nanostructural Materials in Soil Health and Environment. In Dynamics of Advanced Sustainable Nanomaterials and their Related Nanocomposites at the Bio-Nano Interface (pp. 147-170). Elsevier.

Desoky, E. S. M., Merwad, A. R. M., Semida, W. M., Ibrahim, S. A., El-Saadony, M. T., and Rady, M. M. (2020). Heavy metals-resistant bacteria (HM-RB): Potential bioremediators of heavy metals-stressed Spinacia oleracea plant. Ecotoxicology and Environmental Safety, 198, 110685.

Dharupaneedi, S. P., Nataraj, S. K., Nadagouda, M., Reddy, K. R., Shukla,
S. S., and Aminabhavi, T. M. (2019). Membrane-based separation of potential emerging pollutants. Separation and Purification Technology, 210, 850-866.

Gavrilescu, M. (2005). Fate of pesticides in the environment and its bioremediation. Engineering in Life Sciences, 5(6), 497-526.

http://shodhganga.inflibnet.ac.in/bitstream/10 603/3703/15/15_chapter\%207.pdf

Mohapatra, D. P., Brar, S. K., Tyagi, R. D., and Surampalli, R. Y. (2010). Physicochemical pre-treatment and biotransformation of wastewater and wastewater Sludge-Fate of bisphenol A. Chemosphere, 78(8), 923-941.

National Research Council. (1993). In situ bioremediation: When does it work?. National Academies Press.

Nie, J., Sun, Y., Zhou, Y., Kumar, M., Usman, M., Li, J.,. and Tsang, D. C. (2020). Bioremediation of water containing pesticides by microalgae: Mechanisms, methods, and prospects for future research. Science of the Total Environment, 707, 136080.

Padhye, L. P. (2016). Fate of environmental pollutants. Water

Environment Research, 88(10), 1619-1636.

Pandey, B. and Fulekar, M. H. (2012). Bioremediation technology: A new horizon for environmental clean-up. Biology and Medicine, 4 (1), 51-59.

Raper, E., Stephenson, T., Anderson, D. R., Fisher, R., and Soares, A. (2018). Industrial wastewater treatment through bioaugmentation. Process Safety and Environmental Protection, 118, 178187.

Riser-Roberts, E. (1998). Remediation of petroleum contaminated soils: biological, physical, and chemical processes. CRC press.

Shekhar, S. K., Godheja, J., and Modi, D. R. (2020). Molecular Technologies for 
Assessment of bioremediation and characterization of microbial communities at pollutant-contaminated sites. In Bioremediation of Industrial Waste for Environmental Safety (pp. 437-474). Springer, Singapore.

Song, Y., Kirkwood, N., Maksimović, Č., Zheng, X., O'Connor, D., Jin, Y., and Hou, D. (2019). Nature based solutions for contaminated land remediation and brownfield redevelopment in cities: a review. Science of the Total Environment, 663, 568-579.
Varshney, K. (2019). Bioremediation of pesticide waste at contaminated sites. Journal of Emerging Technologies and Innovative Research, 6 (5),

Vázquez-Núñez, E., Molina-Guerrero, C. E., Peña-Castro, J. M., FernándezLuqueño, F., and de la Rosa-Álvarez, M. (2020). Use of Nanotechnology for the Bioremediation of Contaminants: A Review. Processes, 8(7), 826. (http://www.pollutionissues.com/ABo/Bioremediation.html).

\section{How to cite this article:}

Poonam Shakya, Anju Nayak, Joycee Jogi, Ajay Rai, Smita Bordoloi, K. Himani and Aishwarya Lade. 2020. Futuristic Approach to Environment Cleansing: Bioremediation. Int.J.Curr.Microbiol.App.Sci. 9(09): 418-425. doi: https://doi.org/10.20546/ijcmas.2020.909.053 